\title{
El «positivismo fenomenológico» como respuesta al escepticismo: una revisión de la estrategia antiescéptica de Merleau-Ponty
}

\author{
«Phenomenological positivism» \\ as a reply to skepticism: a reappraisal \\ of Merleau-Ponty's anti-skeptical strategy
}

\author{
CLAUDIO CORMICK \\ UBA-Paris VIII/CONICET
}

Recibido: 28/07/16 Aceptado: 15/09/16

\begin{abstract}
RESUMEN
Intentaremos en este trabajo una reconstrucción crítica de la argumentación de Maurice MerleauPonty contra las dudas escépticas sobre nuestra experiencia perceptual, en diálogo con previos acercamientos al problema dentro de la literatura existente, y a efectos de señalar que las estratagemas antiescépticas del fenomenólogo no necesitan ser consideradas como presuponiendo un previo rechazo del realismo metafísico y, correlativamente, como ancladas en una ontología alternativa. Para esto recurriremos a una analogía con la discusión merleaupontyana respecto del relativismo escéptico referido a las «leyes del pensamiento»: si las dudas psicologistas sobre nuestro posible «encierro» en evidencias limitadas, propias de nuestra constitución psíquica, quedan excluidas, esto se debería simplemente a que, para articular la propia tesis escéptica, tenemos que ser considerados capaces de reconocer como evidencias aquellas que, sin embargo, nunca pueden serlo para nosotros. El hecho positivo de la existencia de una forma de experiencia
\end{abstract}

(C) Contrastes. Revista Internacional de Filosofía, vol. XXII-N² (2017), pp. 205-221. ISSN: 1136-4076

Departamento de Filosofía, Universidad de Málaga, Facultad de Filosofía y Letras Campus de Teatinos, E-29071 Málaga (España) 
como lo es la nuestra, señala Merleau-Ponty, se convierte así en la base insuperable de toda evaluación epistemológica.

\author{
PALABRAS CLAVE \\ MERLEAU-PONTY; POSITIVISMO FENOMENOLÓGICO \\ ESCEPTICISMO; PSICOLOGISMO; REALISMO
}

\begin{abstract}
In this article we will attempt a critical reconstruction of Merleau-Ponty's argument against skeptical doubts about our perceptual experience, in a dialogue with previous approaches to the problem within the existing literature, and with the purpose of pointing out that the phenomenologist's anti-skeptical argumental strategies do not need to be considered as presupposing a previous rejection of metaphysical realism and as, correlatively, based on an alternative ontology. To do this, we will appeal to an analogy with Merleau-Ponty's critique of skeptical relativism concerning the «laws of thought»: if psychologistic doubts about our possible «confinement» in limited evidences, proper to our psychic constitution, are excluded, this is simply because, in order to articulate the skeptical tenet itself, we need to be considered capable of acknowledging as such those evidences which, however, cannot be evidences for us. The positive fact of the existence of a form of experience such as ours, according to Merleau-Ponty, becomes in this way the insurmountable basis of any epistemological evaluation.
\end{abstract}

KEYWORDS

MERLEAU-PONTY; PHENOMENOLOGICAL POSITIVISM; SKEPTICISM; PSYCHOLOGISM; REALISM

\title{
I. LA RESPUESTA AL ESCEPTICISMO EN FENOMENOLOGÍA DE LA PERCEPCIÓN Y LO VISIBLE Y LO INVISIBLE: EL DESCUBRIMIENTO DEL ERROR COMO CORRELATIVO DEL DESCUBRIMIENTO DE LA VERDAD
}

En el prefacio de la Fenomenología de la percepción, Merleau-Ponty nos plantea un muy discutido argumento contra el escepticismo. Señala que si dijéramos, como el sensualismo, que no hay sino «estados de conciencia», de manera tal que necesitaríamos «criterios» para distinguir nuestras «percepciones» de nuestros «sueños», entonces

perderíamos de vista el fenómeno del mundo. Porque si puedo hablar de «sueños» y de «realidad», interrogarme sobre la distinción de lo imaginario y lo real, y poner en duda lo «real», es porque esta distinción ya fue hecha por mí antes del análisis, es porque tengo una experiencia de lo real, como de lo imaginario, y el problema, entonces, es [...] describir la percepción del mundo como aquello que funda de una vez y para siempre nuestra idea de la verdad. No hay que preguntarse, por lo tanto, si percibimos verdaderamente un mundo; hay que decir, al contrario: el mundo es aquello que percibimos (Merleau-Ponty 1945: xi; 1985: 16). 
Ampliando el punto, el fenomenólogo agrega:

Más en general, no hay que preguntarse si nuestras evidencias son efectivamente verdades o si, por un defecto de nuestro espíritu, lo que es evidente para nosotros no será ilusorio con respecto a alguna verdad en sí, porque, si hablamos de ilusión, es que hemos reconocido ilusiones, y no hemos podido hacerlo más que en nombre de alguna percepción que, en el mismo momento, se presentara como verdadera, de manera que la duda, o el temor a equivocarnos, afirma al mismo tiempo nuestro poder de develar el error, y no podría desarraigarnos de la verdad (ibíd.).

Más adelante, hacia el final del capítulo sobre el espacio, el fenomenólogo vuelve sobre ideas similares, señalando que

[n]o tenemos por qué elegir entre una filosofía de la inmanencia o un racionalismo que solo da cuenta de la percepción y de la verdad, y una filosofía de la trascendencia o del absurdo que no da cuenta más que de la ilusión o del error. No sabemos que hay errores más que porque poseemos unas verdades, en nombre de las cuales corregimos los errores y los conocemos como errores (Merleau-Ponty 1945: 341; 1985: 309).

Un pasaje similar a estos lo encontramos en el comienzo de Lo visible y lo invisible cuando Merleau-Ponty critica un argumento como el «del sueño, del delirio o de las ilusiones», que nos invita «a examinar si lo que vemos no es 'falso'», argumento que, pese a sí mismo, presupone nuestra «fe en el mundo». Y esto porque, una vez más, «no sabríamos siquiera qué es lo falso, si no lo hubiéramos distinguido algunas veces de lo verdadero»; el escéptico respecto a la percepción olvida «que la 'falsedad' misma de los sueños no puede ser extendida a las percepciones, porque aquella no aparece más que relativamente a estas, y porque hace falta, si uno debe poder hablar de falsedad, que tengamos experiencias de la verdad» (Merleau-Ponty 1964: 19; 2010: 19). Pero si el escéptico elide esta distinción, interna a nuestra experiencia, entre la verdad y el error, y se pregunta si no debemos por el contrario «nivelar» el conjunto de nuestra experiencia como cayendo ella misma del lado del error, esto se debe, continúa Merleau-Ponty, a que el argumento está «impregnado» de «ingenuidad puesto que solo iguala la percepción y el sueño cuando los pone ante la mirada de un Ser que no estaría sino en sí mismo» (Merleau-Ponty 1964: 20; Merleau-Ponty 2010: 19).

\section{LA RELACIÓN CON EL REALISMO METAFÍSICO EN LOS ARGUMENTOS ANTIESCÉPTICOS}

La respuesta merleaupontyana que acabamos de ver puede analizarse, a grandes rasgos, en términos de que el escepticismo solo puede tener base si le 
atribuye alguna fiabilidad al carácter autocorrectivo de nuestra vida perceptiva, esto es, si el escepticismo concibe, igual que el pensamiento prerreflexivo, que nuestra experiencia no puede ser de conjunto ilusoria, aunque parcialmente lo sea. Como señala Douglas Low, los «argumentos escépticos siempre presuponen la aceptación de una percepción [...] subsecuente que pone en cuestión la primera. La única manera de que una percepción sea desafiada como falsa es desde el punto de vista de otra que haya sido aceptada como verdadera» (Low 2000: 10). En palabras de Marcus Sacrini, es «porque uno tiene la experiencia de episodios perceptivos confiables en contraste con la experiencia de episodios de sueños que uno puede distinguir el contenido conceptual relacionado con 'percepciones' y con 'sueños'. Sin embargo [...], cada episodio perceptivo aislado puede ser puesto en duda en contraste con nuevos episodios (supuestamente más confiables)» (Sacrini 2013: 723). Por su parte, Bernard Flynn ha señalado correctamente que el rechazo merleaupontyano del escepticismo presupone la previa puesta en cuestión de una ontología realista que postulara un «ser en sí mismo». Como señala este intérprete, ateniéndose sin duda a -al menos- parte de la letra de la argumentación del fenomenólogo, hay una primera «forma de escepticismo que rápidamente despacha, a saber, el pirronismo [...]. Es una forma de pensar que alberga la idea de 'la verdad en sí misma'», que sostiene la «concepción de un 'ser en sí mismo'», «y por medio de esta idea amenaza todas nuestras experiencias reales», cuestiona «nuestra vida interna, llena de representaciones». Frente a esto, la crítica de Merleau-Ponty se llevaría adelante «de una forma tradicional», señalándole al escéptico «presuposiciones no reconocidas y no problematizadas; por ejemplo, una 'teoría representacional de la conciencia' y una idea de 'verdad en sí misma'» (Flynn 2009: 124-125).

Esta lectura es correcta, pero, creemos insuficiente: el problema es si alcanza con señalarle al escéptico el hecho de que se está apoyando en estas nociones realistas sobre el ser y la verdad; si no es necesario dar un paso más allá y refutar la plausibilidad de estas nociones. Como ha puesto de manifiesto Henry Pietersma, el propio Merleau-Ponty acepta que la posición escéptica conserva alguna plausibilidad si asumimos algo que el fenomenólogo descarta sin más «como una ingenuidad», a saber, si aceptamos el supuesto «de que nuestras percepciones constituyen conocimiento si y solo si ellas captan una realidad objetiva más allá de toda experiencia [...], un ser que existe completamente en sí mismo», que puede ser contrastado «con todas nuestras percepciones e imaginaciones» (Pietersma 1989: 103. Subrayado en el original). En otras palabras, un escéptico respecto del valor cognitivo de la percepción que se apoyara en premisas realistas podría reconocer que, obviamente, la experiencia que tenemos de lo que llamamos error perceptual es correlativa de la experiencia de lo que consideramos una desmentida de ese error. Pero esta simplemente no es la distinción que le interesa. Como señala Pietersma, el escéptico 
«niega, precisamente, no que hagamos una distinción tal, sino que, en última instancia, ella pueda ser justificada» (ibíd. Subrayado nuestro). Si aquí se trata de algo más que de una «geografía conceptual» del lenguaje ordinario, si se trata de defender la distinción misma, hace falta algo más, puesto que aún no hemos dicho nada que afecte a un realista metafísico. No se ve cómo la réplica merleaupontyana, que subraya el modo en que lo que experimentamos como error solo tiene tal carácter como correlato de lo que experimentamos como una percepción fidedigna podría aplicarse al tipo de escepticismo que tiene una base realista metafísica, es decir, al tipo de escepticismo que no se pregunta por la posible inadecuación de nuestras percepciones presentes con respecto a la clase de desmentida que puede provenir de percepciones futuras, sino que, de manera mucho más radical, pone en cuestión el conjunto de nuestra experiencia perceptual en nombre de una realidad no percibida. Un escepticismo de base realista simplemente utilizaría de modo diferente las nociones de «realidad» $\mathrm{e}$ «ilusión»; la «realidad» que se contrapone a la ilusión ya no sería aquello que experimentamos, y la «ilusión» lo que es desacreditado como tal en vistas de experiencias más fiables, sino que, de un modo -si se quiere- metafórico, toda nuestra experiencia podría quedar relegada al rango de algo como los sueños o las alucinaciones. Un dualismo de este tenor señalaría que la realidad trascendente, precisamente porque es trascendente, y como tal ontológicamente diferente de nuestros contenidos de conciencia, podría ser radicalmente distinta del modo en que nos la representamos, y estaríamos incapacitados de descubrir este error dado que nos encontramos «encerrados» en el campo de la inmanencia, detrás de nuestro «velo de ideas». Si este realismo entra en escena, lejos de que él implique el tipo específico de escepticismo que es refutado por nuestra experiencia cotidiana de la distinción realidad-ilusión, lo que tenemos es más bien la introducción de un tipo de tesis escéptica frente a la cual no sería una respuesta en absoluto el simplemente constatar que ella no «encaja» con nuestras distinciones cotidianas.

Según declara Pietersma en lo que ve como una confluencia entre su propia posición y el enfoque merleaupontyano, «hay una conexión» entre esta noción de una «realidad objetiva más allá de toda experiencia» y el «escepticismo filosófico». En sus palabras, lo que está en juego es

la noción del ser que no incluye ninguna referencia a nuestras capacidades cognitivas. Ser, en esta perspectiva, no implica ni que sea posible ni que sea imposible hacer afirmaciones racionales acerca de él. Sin embargo, se dice que nuestras creencias son verdaderas solamente en virtud de lo que existe en este sentido. $\mathrm{Y}$ si no son verdaderas, no pueden contar como conocimiento (ibíd: 104).

La tesis realista señala que la verdad de nuestras creencias sobre lo real se determinaría, entonces, a partir de la relación con una realidad de la cual 
no podemos decir de antemano que ella sea cognoscible. Así, no solo no está garantizado que de hecho, en determinado momento, nuestras creencias perceptuales sobre el mundo sean verdaderas, sino que tampoco está garantizado que podamos llegar a tener tales creencias verdaderas más adelante: la realidad no se define como el correlato de operaciones actuales o siquiera posibles de conocimiento, y en consecuencia ella podría, concebiblemente, estar más allá de nuestras capacidades cognitivas de conjunto. «De modo que», concluye Pietersma, «lo que Merleau-Ponty enfatiza, a saber, que las percepciones son en nuestra conciencia diferentes de los sueños, no prueba que equivalgan a un conocimiento del mundo real, objetivo» (ibíd. Subrayado nuestro). ${ }^{1}$

Pasando en limpio, tenemos entonces dos formulaciones diferentes de la distinción conocimiento-error aplicada a la percepción. Sin pretensiones de ofrecer definiciones, podemos al menos clarificar ciertas condiciones generales:

Distinción conocimiento-error según el fenomenólogo: una creencia perceptual particular constituye conocimiento si y solo si nos pone en contacto con lo «real» experimentado, esto es, si no es desmentida por otras creencias perceptuales particulares. Sin embargo, no está en cuestión la posibilidad de que el conjunto de la experiencia perceptual sea engañoso: lo real es lo que percibimos (i.e., su cognoscibilidad es necesaria, está garantizada por definición).

Distinción conocimiento-error según el realista metafísico: una creencia perceptual particular (y la experiencia perceptual en su conjunto) constituye conocimiento si y solo si capta una realidad objetiva que, si bien es accesible a nuestra experiencia, no se define en virtud del contacto con esta (i.e., su cognoscibilidad es contingente).

Hagamos dos señalamientos sobre esta presentación de la diferencia filosófica en juego aquí. Ante todo, intentamos así hacer justicia a la idea de que ambas formulaciones no están, en rigor, en una relación de mutua exclusión: el realista no necesita rechazar en principio la condición de que, para ser considerada verdadera, una creencia perceptual no haya sido desacreditada por experiencias posteriores; simplemente considera que es necesario reforzarla exigiendo algo más: una creencia perceptual tiene que cumplir con la condición de no resultar desmentida en su propio terreno, pero también tiene que estar avalada por alguna

1 En rigor, junto con esta tesis realista, y como presuntamente indisociable de ella, Pietersma defiende una tesis sobre el carácter de «relación externa» que sostienen nuestras creencias respecto de la realidad; esto es, la posición según la cual «la verdad de una creencia depende de su acuerdo con la realidad y nada más. De acuerdo a esta perspectiva, ningún análisis de una creencia como tal puede, en sentido estricto, probar que sea verdadera. En términos ligeramente diferentes, la relación entre el conocedor y lo que conoce es una relación externa, no interna» (ibíd). 
evidencia de que existe un estado de cosas, más allá de nuestra experiencia, que se corresponde con aquella. Lo cual nos lleva a la segunda precisión, más importante: es solamente en la formulación realista de la distinción que no solo cada creencia perceptual en particular sino la experiencia perceptual en su conjunto es susceptible de ser calificada epistemológicamente como fidedigna o no; para el fenomenólogo, la percepción en su conjunto no puede nunca ser errónea, y la distinción conocimiento-error es interna a ella; se refiere, únicamente, a creencias perceptuales particulares. Así las cosas, si el realista metafísico exige más que el fenomenólogo para atribuirle valor de conocimiento a la percepción en su conjunto, si no acepta la idea de que la distinción conocimiento-error deba ser interna a nuestra experiencia, ¿le queda al fenomenólogo algún argumento que demuestre la insostenibilidad de un escepticismo con base realista metafísica?

\section{III. ¿ES LA «UNIDAD METAFÍSICA SUJETO-OBJETO» NECESARIA, O APLICABLE, PARA LA RESPUESTA MERLEAUPONTYANA?}

En la lectura de Pietersma, Merleau-Ponty intentaría responder a este desafío intentando reabsorber la realidad objetiva dentro del marco de una «unidad metafísica» del sujeto con el objeto, puesto que solo así quedaría garantizada la exclusión de la duda escéptica. De acuerdo al intérprete, ahondando en lo que hemos visto previamente, el

realismo metafísico con el que se compromete el escéptico radical plantea una relación externa entre sujeto y objeto. El epistemólogo trascendental, por lo tanto, piensa que uno no puede librarse del escepticismo sin rechazar también el realismo metafísico, y, de manera acorde, se propone mostrar que la relación sujeto-objeto no es, en última instancia, externa (Pietersma 2000: 22).

En el caso particular de Merleau-Ponty, la conversión de la relación sujetoobjeto en «interna», y las consecuencias de esta transformación para la argumentación antiescéptica, cobran según Pietersma la siguiente forma:

El contexto de la percepción primordial, según nos asegura Merleau-Ponty, nos asegura de la verdad y tiene, de forma acorde, la virtud de ser capaz de contener al escepticismo; esto es, [el contexto] tiene lo que el trascendentalista busca en la matriz unitaria de la experiencia; a saber, que sea autocontenida y por lo tanto asegurada contra cualquier cosa que pueda ser exterior a ella (ibíd: 178).

En otras palabras, para Pietersma,

la metafísica de Merleau-Ponty es del tipo que ha sido característico del pensamiento trascendental [...]. La dualidad epistémica de sujeto y objeto, de hecho innegable, no puede ser aceptada por el filósofo trascendental como un hecho 
último, porque esto le daría legitimidad al realismo filosófico con respecto a los objetos del conocimiento y, como señaló Kant, le abriría las puertas al escepticismo. Mientras un realista no está demasiado preocupado por las relaciones exteriores como la de sujeto y objeto, un filósofo trascendental solo puede lograr aceptar la dualidad si ella puede ser concebida como, en algún sentido, derivada de una unidad (ibíd: 160).

De acuerdo a este intérprete, el fenomenólogo está preocupado por demostrar

que nunca perdemos contracto con la verdad y que el escepticismo no es una amenaza. Quiere decir que [...] es seguro que el error será descubierto, y no necesitamos temer que podamos permanecer atrapados sin escapatoria en la falsedad. La búsqueda de la verdad está por lo tanto asegurada (ibíd: 154).

Ahora bien, ¿en qué se basaría Merleau-Ponty, según este intérprete, para sostener su convicción en el valor cognitivo de la percepción? De acuerdo a Pietersma, el fenomenólogo francés introduce una «unidad metafísica para sostener y asegurar su doctrina epistemológica, la cual a su vez intenta mostrar que el conocimiento es posible. Epistemológicamente, sostiene que la percepción corporizada es conocimiento» (ibíd: 161). En esta línea de análisis, pues, los argumentos antiescépticos no deben leerse como autocontenidos, sino en complementariedad con los pasajes en los que el fenomenólogo establece la homogeneidad ontológica entre el sujeto percipiente y la realidad percibida; esto es, textos como aquel en que Merleau-Ponty constata que,

a la vez, vemos las cosas, en su lugar, donde ellas están según su ser, que es mucho más que su ser-percibido, y estamos alejados de ellas por toda la consistencia de la mirada y del cuerpo: es que esa distancia no es lo contrario de esa proximidad, está profundamente en consonancia con ella, es sinónimo de ella. Es que la consistencia de la carne entre el vidente y la cosa es constitutiva de la visibilidad de ella y de la corporalidad de él; no es un obstáculo entre ambos, es su medio de comunicación (Merleau-Ponty 1964: 176; 2010: 123).

Pietersma lee este pasaje de forma lapidaria: «En otras palabras», interpreta, «todo lo que podría haber contado como un argumento contra el valor cognitivo de la percepción corporizada, 'el espesor de la mirada y del cuerpo', sufre aquí una transformación de su valor [transvaluation]. Las distorsiones debidas a la corporeidad se convierten en una iniciación al ser de las cosas» (Pietersma 2000: 161). De esta manera, «la unidad introducida por el filósofo» tiene por «propósito [...] asegurarnos que la relación entre el conocedor y lo conocido no es puramente externa (como querría el realismo) sino que el valor cognitivo de la percepción primordial involucra el ser mismo de las cosas» (ibíd:: 162). 
Sería entonces en virtud de esta ontología que, en el plano epistemológico, Merleau-Ponty rechaza el escepticismo; se trataría así de que el fenomenólogo se ha garantizado de antemano que «la visión y sus objetos se ajusten, que su relación no sea simplemente una cuestión de hecho, externa y por lo tanto, en algún sentido, accidental», sino que estén «hechos el uno para el otro. Ser percibido no es algo que simplemente le ocurre a las cosas por mero accidente: es esencial a ellas el ser vistas» (Pietersma 2000: 162).

Tomémonos estos señalamientos al pie de la letra: de acuerdo a ellos, Merleau-Ponty no tiene, contra el realismo metafísico según el cual las cosas podrían ser otra cosa que el correlato de nuestra experiencia, el aval de sus argumentos antiescépticos; a la inversa, si existe una conexión entre el rechazo del realismo y el rechazo del escepticismo, tendrá que ser el realismo el que caiga primero, bajo los embates de una ontología de la carne, para que el valor cognitivo de la percepción quede garantizado. ${ }^{2}$ Esta interpretación es interesante precisamente por alejarse de modo notable de lo que Merleau-Ponty declara estar haciendo: como sabemos, el fenomenólogo no presenta sus argumentos antiescépticos como requeridos de haber defendido, de manera independiente, una ontología alternativa, de modo que quizá la lectura «a contrapelo» propuesta por Pietersma nos obligue a poner de manifiesto presupuestos sin los cuales la argumentación merleaupontyana no funcionaría. En este mismo sentido, el intérprete había sostenido, una década antes, que el argumento antiescéptico acerca del error y la ilusión se apoyaba en una previa posición anti-realista: no podríamos dentro de la filosofía merleaupontyana, interpreta Pietersma, distinguir entre percepciones «sobre la base del hecho de que algunas tienen objetos que les corresponden y otras no, sea o no que los seres humanos puedan realmente aplicar esa distinción. Incluso la sugerencia de la posibilidad de un error no reconocido como tal no tiene ningún sentido desde la perspectiva anti-realista [...] sostenida por Merleau-Ponty» (Pietersma 1989: 121).

2 Mutatis mutandis, también encontramos en otros autores, de posiciones más cercanas a las de Merleau-Ponty, la tesis de que la discusión epistemológica sobre el escepticismo es secundaria respecto de la discusión ontológica sobre el dualismo, esto es, sobre el estatuto de los objetos físicos y nuestra representación de ellos: para Lawrence Hass, por ejemplo, la discusión merleaupontyana acerca de la percepción «toma por blanco la concepción de que la percepción está localizada en mi mente o mi cerebro, de que la percepción es una pantalla interna que cubre la realidad externa. Son precisamente estos elementos ontológicos -estos artefactos del dualismo- los que sostienen la entera concepción y el lenguaje sobre la percepción como una 'representación subjetiva'. Y [...] son estos elementos los que acarrean el idealismo, escepticismo y subjetivismo que acechan la filosofía post-cartesiana» (Hass 2008: 35-36). Es por esto, según el autor, que es legítimo responder el desafío escéptico en términos de que «si uno va a dudar realmente, honestamente, sobre todas las cosas, entonces a priori no se puede sostener nada, $\mathrm{y}$, en particular, una ontología dualista» (ibíd: 40). 
Veamos qué es exactamente lo que el fenomenólogo nos diría, entonces, acerca del error. De acuerdo a Pietersma, es la doctrina de una «unidad metafísica» la que nos asegura que no permaneceremos en el error: el modo mismo de ser de las cosas es captado por la forma en que tenemos de conocerlas. Pero, pasando en limpio, esto tendría que significar:

que -primer paso- nuestra experiencia del mundo podría en principio no ponernos en contacto con la realidad; que podríamos estar definitivamente separados de ella y subsistir en un (concebible) error permanente, insuperable;

pero que -segundo paso- un análisis sobre la «unidad metafísica» revelada por nuestra experiencia nos asegura que esta posibilidad, concebible, no se realiza de hecho; tal «unidad» vendría a cerrar el bache de una posibilidad, en principio abierta, de que el mundo real no sea tal como lo experimentamos.

Sin embargo, como es bastante obvio, la clase de «unidad» que está presentada aquí no puede ser una respuesta satisfactoria para el problema de si conocemos el mundo objetivo, puesto que ella se refiere, desde el vamos y conscientemente, a la correlación entre los objetos experimentados y nuestra experiencia de ellos; decir que «el conocer o el ver» es realizado «por un ser que no es fundamentalmente diferente del mundo que él explora» (Pietersma 2000: 161) solo puede resultar de alguna pertinencia contra el escéptico si disponemos, además, de algún argumento que nos asegure que no hay «otro» mundo aparte del mundo de nuestra experiencia. Quien estuviera dispuesto a asumir, siquiera como hipótesis, la idea de que la realidad objetiva es otra cosa que el correlato de nuestras posibles operaciones cognitivas -quien estuviera dispuesto a asumir un mundo «en sí» compuesto de objetos «reales» que, por ejemplo, no requieren ser captados a través de las variaciones perspectivas por medio de las cuales nosotros accedemos a ellos- no se sentiría particularmente impresionado por una respuesta que, en definitiva, no hace más que formular una correlación interna a nuestra experiencia. Creemos, en consecuencia, que la respuesta merleaupontyana está en otro plano: el fenomenólogo necesita excluir la idea de una realidad extraempírica únicamente por relación con la cual nuestras creencias perceptuales habrían de ser verdaderas, y la exclusión de esta alternativa pasa por el rodeo del problema conceptual, lingüístico, de la inaplicabilidad que predicados como «verdad» $\mathrm{o}$ «error» tendrían para nosotros bajo una interpretación realista.

IV. «SI PARA MÍ PUEDE LLAMARSE VERDAD»: EL «POSITIVISMO FENOMENOLÓGICO» De Merleau-Ponty y La EXIGencia DE APLiCABILIDAD EN CONCRETO DE LOS PREDICADOS 
Intentemos ahora desarrollar esta línea de análisis. Fundamentarla requiere que ampliemos la discusión más allá de los loci classici del debate entre Merleau-Ponty y el escepticismo; esto es, el primer capítulo de Lo visible y lo invisible, el prefacio de la Fenomenología de la percepción, y el final del capítulo acerca del espacio. Necesitamos tomar en consideración el tipo de argumento que Merleau-Ponty aplica, no al escepticismo respecto a los sentidos, sino al escepticismo con respecto a las «leyes de nuestro pensamiento», esto es, a nuestras facultades intelectuales, y que presenta de hecho -esto es, los destaque el autor o no- puntos de complementariedad con su discusión acerca de la fiabilidad de la experiencia perceptual. Existe un problema que podemos plantearnos en un nivel genérico, más acá de la cuestión de cuál de nuestras «facultades»-percepción o entendimiento- esté puesta en cuestión, y es el de si es al menos concebible la idea de que pueda ser realmente un error aquello que para nosotros, de acuerdo a nuestras capacidades cognitivas, es una verdad; esto es, el problema de si la distinción entre error y conocimiento (la distinción, mutatis mutandis, entre ilusiones y experiencias fidedignas) puede dejar de ser interna a lo que experimentamos y utilizarse en un sentido «traslaticio» como lo hace el escéptico de orientación realista. Pues bien, es precisamente esto lo que, al discutir la amenaza psicologista a la fiabilidad de nuestro pensamiento, el fenomenólogo rechaza; en resumidas cuentas, su punto es que la postulación de una presunta evidencia que permanece más allá de todo acceso que nosotros podamos tener es simplemente un contrasentido; nosotros nunca podríamos otorgarle a esa presunta evidencia el estatuto de tal, y como tal nunca podría valer contra las evidencias de las que sí disponemos.

Es de hecho este «escepticismo» el que, textualmente, es objeto de la crítica merleaupontyana en el capítulo sobre «El cogito»: se trata de una posición que «reduce la evidencia a la apariencia» por la vía de señalar, por un lado, que «todas mis verdades no son, después de todo, más que evidencias para mí y para un pensamiento que esté hecho como el mío, ellas son solidarias de mi constitución psico-fisiológica»-meramente relativas, porque «[u]no puede concebir otros pensamientos que funcionen según otras reglas»-, y plantear también que, por otro lado, no podemos dejar de pensar de acuerdo a nuestras reglas, porque «estamos encerrados en nuestra constitución psico-fisiológica, que es un simple hecho, del mismo modo que la forma de nuestra cara, o el número de nuestros dientes» (Merleau-Ponty 1945: 455; 1985: 406). Sin embargo, de acuerdo al fenomenólogo, esta concepción «supone una referencia tácita a un saber y a un ser absolutos con respecto a los cuales nuestras evidencias de hecho son consideradas como inadecuadas» (ibíd.). Por el contrario, y permitámonos citar esta respuesta in extenso, para una concepción fenomenológica 
[1]as leyes de nuestro pensamiento y nuestras evidencias son ciertamente hechos, pero inseparables de nosotros, implicados en toda concepción que podamos formarnos del ser y de lo posible. No se trata de limitarnos a los fenómenos, de encerrar la conciencia en sus propios estados mientras se preserva la posibilidad de otro ser más allá del ser aparente, ni de tratar nuestro pensamiento como un hecho entre los hechos, sino de definir el ser como lo que se nos aparece y la conciencia como hecho universal. Yo pienso, y tal o tal pensamiento se me aparece como verdadero [...] y [...] toda otra verdad, en nombre de la cual pueda devaluar a aquella, si para mí puede llamarse verdad, tiene que concordar con el pensamiento «verdadero» cuya experiencia tengo. Si trato de imaginar unos marcianos, o ángeles, o un pensamiento divino, cuya lógica no sea la mía, será preciso que este pensamiento marciano, angélico o divino figure en mi universo y no lo haga estallar. Mi pensamiento, mi evidencia, no es un hecho entre otros muchos, sino un hecho-valor que envuelve y condiciona todo otro hecho posible (Merleau-Ponty 1945: 455-456; 1985: 406-407).

Desglosemos un poco este denso pasaje. Ante todo, notemos que MerleauPonty señala, abiertamente, que tenemos que «definir el ser como lo que se nos aparece», con lo cual la pregunta por la posibilidad de que no conozcamos lo real queda excluida de antemano; que el ser es cognoscible, que cae bajo el alcance de nuestras capacidades epistémicas, es una verdad necesaria, pero porque está garantizada por definición. Tenemos aquí claramente el enfoque diametralmente opuesto al adoptado por un realista como Pietersma cuando habla de una concepción del ser que no incluye ninguna referencia a nuestras capacidades cognitivas. En segundo lugar, reaparece aquí la correlación entre un error desmentido y una verdad sobre la cual nos apoyamos para desmentirlo, nexo que ya habíamos visto para el caso de las creencias perceptuales y que, en ese contexto, significaba que la duda nunca puede ser absoluta, sino que necesita apoyarse en algún dar-por-verdadero. Ahora bien, si el argumento contra el relativismo psicologista estuviera formulado en exactamente los mismos términos, permaneceríamos frente al problema de cómo justificar la forma misma en que distribuimos conocimiento y error, en particular teniendo en mente lo que hemos descrito como un uso diferente, realista, de las nociones en cuestión.

No obstante, lo que queremos argumentar aquí es que Merleau-Ponty introduce, en la discusión contra el psicologista, algo más. Lo que está exigiendo el fenomenólogo es que cualquier atribución del predicado «verdadero», para que se trate realmente de una atribución de verdad y no estemos simplemente usando la palabra de forma idiosincrática, tiene que poder entrar en relación con nuestras «verdades». ¿Es posible que nuestras distinciones cotidianas entre el conocimiento y el error «distribuyan» las creencias de un modo incorrecto con respecto al «ser objetivo»; que lo que clasificamos como verdadero sea en rigor 
falso? Concedido, pero es el escéptico-realista quien tiene que explicar por qué seguir llamando «verdad» al estatuto que, presuntamente, podrían tener ciertas creencias que, sin embargo, y por hipótesis, nunca podríamos reconocer como tales. Lo que de hecho está cuestionando Merleau-Ponty es la plausibilidad de sostener conceptos de «verdad» $\mathrm{y}$ «error» que necesitan moverse en un plano enteramente paralelo a aquel de lo que de hecho llamamos verdad y error, conceptos que, por hipótesis, jamás podrían ser aplicados en concreto por nosotros. Si la captación de la presunta verdad de una proposición p está por principio fuera de nuestro alcance -si, por nuestros límites epistémicos, nosotros estamos condenados a creer que p es falsa, o un sinsentido-, ya ni siquiera se ve cómo se justificaría que afirmáramos que p, en algún sentido, podría ser verdadera. La desmentida global de nuestras creencias es una para la cual el escéptico guarda permanentemente el rótulo de «posible»-a nuestras creencias «posiblemente» les quepa el predicado de «falsas», y a otras que negaríamos o no concebiríamos «posiblemente» les convenga el de «verdaderas»-, pero se trataría de una posibilidad que, de acuerdo a su propia tesis escéptica, nunca puede realizarse para nosotros.

Podemos reforzar nuestra interpretación a partir de un segundo pasaje en que Merleau-Ponty argumenta contra el escepticismo respecto de nuestras capacidades intelectuales, y que se encuentra en el curso La fenomenología y las ciencias del hombre. En una presunta interpretación de Husserl (la fidelidad de la cual no necesitamos suscribir), Merleau-Ponty declara por qué la contingencia de las formas de nuestro pensamiento no supone quedarnos encerrados en evidencias parciales a las cuales siempre podríamos por principio contraponerle otras: si tratamos de concebir una subjetividad que funcionara de manera totalmente heterogénea a nosotros, por ejemplo, un «ángel que pensara según leyes radicalmente diferentes de las de la humanidad y viniera así a llenar de dudas les leyes del pensamiento humano», la respuesta merleaupontyana es, simplemente, que «ese ángel no puede ser pensado por mí. Cuando lo concibo, no concibo nada» (Merleau-Ponty 1963: 9; s/f: 26). O, más in extenso:

Las leyes de nuestro pensamiento son para nosotros leyes del ser [...], no porque nos comuniquemos con un pensamiento prepersonal, sino porque aquellas son para nosotros absolutamente coextensivas a todo lo que podamos afirmar, y porque, si quisiéramos pensar otras que las contradigan, por ejemplo, algún pensamiento sobrehumano, divino o angélico, nos sería necesario, para reconocerle un sentido a esos nuevos principios, sumergirlos bajo los nuestros de manera que no fueran ajenos a nosotros. Si los ángeles son verdaderamente pensados por nosotros y es necesario que lo sean, sin lo cual no podemos argumentar sobre ellos, pueden ser pensados como pensadores solo en cuanto ellos se asemejan, por las leyes 
de nuestro pensamiento, a nosotros (Merleau-Ponty 1963: 9; Merleau-Ponty s/f: 25-26. Subrayado nuestro). ${ }^{3}$

Así como en el capítulo «El cogito» la argumentación del fenomenólogo no necesitaba ir más allá de afirmar que, incluso si no podemos dejar de pensar según las leyes de nuestro pensamiento, cualquier verdad que para nosotros «pudiera llamarse verdad» tendría que poder adaptarse a las condiciones de aquello que, en nuestra experiencia, ha contado como verdadero, y desde este punto de vista el énfasis no está puesto en las presuntas garantías trascendentes que tiene nuestro modo de pensar, sino en el hecho más prosaico de que seremos nosotros, en última instancia, quienes tengamos que atribuir razonablemente predicados como «verdadero», así también la tesis del curso de 1951 es que somos nosotros -nosotros los humanos, y en esto se incluye tanto al «positivista fenomenológico» como a su adversario relativista escéptico- quienes tenemos que poder «pensar como pensadores» a unos presuntos sujetos epistémicos cuyas formas de pensamiento no podemos captar en absoluto, y somos nosotros puesto que somos nosotros quienes estamos embarcados en «argumentar sobre ellos». Una vez más, la argumentación antiescéptica no se apoya en una ontología, sino en la exigencia de la aplicabilidad justificada de un predicado, el de «pensador» o «sujeto cognoscente». Si no es sobre la base de cierta similitud con nuestro pensamiento, aquel «radicalmente otro» que se nos pide que concibamos como un pensador, como un sujeto cognoscente, no puede serlo para nosotros en absoluto. ${ }^{4}$

Como se notará, esta reconstrucción tiene la ventaja, para la posición del «positivista fenomenológico», de exigir a los predicados de «verdad» $\mathrm{y}$ «error»

3 Desafortunadamente, este curso de Merleau-Ponty ha sido rara vez analizado desde el punto de vista epistemológico que nos interesa aquí; los acercamientos al respecto en la literatura existente (Sabot 2013, Bimbenet 2011, Bimbenet 2004) se han referido casi exclusivamente al problema antropológico de la «dualidad» del hombre que da inicio al curso. Cfr. no obstante Toadvine (2002, en particular la breve referencia al positivismo fenomenológico en 253-254) para un acercamiento más cercano a cuestiones de teoría del conocimiento.

4 Esta línea argumental parece presentar similitudes con el modo en que, según Davidson, un lenguaje que no pudiéramos traducir al nuestro nos plantearía el problema de en qué sentido estamos en presencia de un lenguaje en absoluto, y esto funciona como suficiente reparo contra la duda escéptica que sería generada por la postulación de esquemas conceptuales que articularían una presunta realidad incognoscible para nosotros. La estrategia davidsoniana para excluir la idea de que quizá «nuestro» lenguaje nos encierre en «nuestras» experiencias y por lo tanto exista una realidad a la que sin embargo no podemos acceder apelaba, simplemente, a la idea de que no podríamos decir, en concreto, que determinada actividad cuenta como «lenguaje» si no podemos traducir los enunciados de este lenguaje «inconmensurable»; apelaba, en última instancia, al criterio elemental de que para hablar, nosotros, de un «lenguaje intraducible», tenemos que poder primero considerarlo, nosotros, como un lenguaje. Cfr. Davidson (1991: 185-186). 
una propiedad muy mínima, que concierne a su mera condición de predicados, y que por lo tanto puede sensatamente defender como una exigencia razonable también para predicados de cualquier otro tipo, no necesariamente epistemológicos: incluso si un determinado predicado carece de condiciones de aplicación enunciables estrictamente en términos de condiciones necesarias y suficientes, tiene que tener alguna condición de aplicación. La «verdad» en el sentido criticado por Merleau-Ponty al referirse al psicologismo en la Fenomenología, la condición de «pensador» extendida en Las ciencias humanas... a los portadores de estas presuntas verdades en sentido realista, simplemente no cumplirían con este requisito elemental, requisito que está lo suficientemente distanciado de los términos habituales de la discusión realismo-antirrealismo como para que no se pueda acusar al fenomenólogo de estar cometiendo una petición de principio.

Y, mutatis mutandis, toda esta línea argumental puede aplicarse también para el caso de nuestras creencias específicamente perceptuales. Si la posición de Merleau-Ponty es coherente -y no vemos por qué no habría de serlo-, el autor tiene que exigir que, cuando hablamos de estas creencias como verdaderas o falsas, la noción de verdad que está en juego aquí sea una que seamos capaces de aplicar en concreto, aplicarla a tal o cual creencia particular. Una evaluación del valor de nuestras creencias como falsas con respecto a una realidad incognoscible introduciría, en todo caso, distinciones paralelas a las que hacemos cuando, $a$ partir de nuestra experiencia del mundo, diferenciamos «nuestras» verdades de «nuestros» errores; estas distinciones, apoyadas en las facultades cognitivas que de hecho tenemos, son aplicables, podemos en concreto considerar que una experiencia se nos presenta como fidedigna o que otra se revela retrospectivamente como un error, y frente a estas, el modo en que habla de «verdad» y «error» el realista metafísico corre el riesgo de introducir conceptos que jamás podríamos utilizar. La premisa en que se estaría apoyando Merleau-Ponty para rechazar el escepticismo de base realista metafísica no sería propia de una «geografía conceptual»-la mera constatación de que tenemos una distinción verdad/error basada en nuestra experiencia- ni de un análisis genético, sobre el mero origen de nuestras distinciones conceptuales -que podría tratar de insistirle al escéptico realista que también sus propios conceptos tienen origen en la experiencia perceptual- sino una que no se ve fácilmente que el realista pueda cuestionar, a saber: sea o no que creamos que existe una realidad independiente de nuestras facultades cognitivas (lo cual el fenomenólogo no puede denegar sin cometer una petición de principio), sigue siendo cierto que los predicados de «verdad» y «error» deben ser «nuestros» al menos en el sentido mínimo de que somos nosotros quienes debemos poder aplicarlos; simplemente no se ve cómo habría de justificarse la introducción de un tipo de distinción verdad-error que jamás seríamos capaces de aplicar a ningún caso particular. 


\section{CONCLUSIONES}

Según hemos intentado desarrollar en las secciones precedentes del presente trabajo, la discusión merleaupontyana contra el escepticismo referido a la percepción no puede dar por sentado que la distinción conocimiento-error que resulta pertinente para el debate sea la que distingue, dentro de nuestra experiencia, entre percepciones fiables y aquellas que no lo son; si, por el contrario, debe poder replicar a las demandas del realista metafísico -en cuanto a que el título de conocimiento solo puede atribuirse a la percepción si esta nos pone en contacto con un ser «objetivo»- entonces será necesario complementar la respuesta al pirronismo de un modo tal que quede excluida la posibilidad de que nuestra experiencia de conjunto pueda resultar «ilusoria» $\mathrm{o}$ «distorsionada» respecto de lo real. Pues bien, el hecho es que Merleau-Ponty efectivamente tiene un argumento para excluir este tipo de duda, pero es un argumento conceptual, concerniente al sentido que pueda tener llamar «falsas» a nuestras creencias en oposición a presuntas «verdades» que nunca puedan dársenos como tales, que nunca puedan caer bajo el alcance de nuestras facultades cognitivas. Este tipo de argumento contra la posibilidad misma de un engaño global es susceptible de ser extrapolado al debate merleaupontyano sobre la experiencia perceptual, pero en virtud de una simple atribución de coherencia al autor: es la clase de argumento que el fenomenólogo adopta con respecto a la hipótesis escéptica de un carácter insuperablemente distorsionado de nuestra capacidad intelectual, y podemos asumir, mutatis mutandis, que resulta plausible aplicarlo también al caso que nos ocupa. Una discusión ulterior, sobre la aceptabilidad de la estratagema argumentativa propuesta por Merleau-Ponty, excedería las proporciones del presente trabajo. Creemos haber logrado, sin embargo, señalar en una dirección potencialmente fructífera para el análisis, en la que la literatura sobre la discusión merleaupontyana con el escepticismo no se ha detenido hasta el momento.

\section{REFERENCIAS BIBLIOGRÁFICAS}

BIMBENET, ETIENNE (2004), Nature et humanité. Le problème anthropologique dans l'œuvre de Merleau-Ponty, Vrin, Paris.

- - , (2011), Après Merleau-Ponty. Études sur la fécondité d'une pensée, Paris, Vrin.

DAVIDSON, DONALD (1991), «On the very idea of a conceptual scheme», Essays on truth and interpretation, Oxford, Oxford University Press.

FLYNN, BERNARD (2009), «Merleau-Ponty and the Philosophical Position of Skepticism», en Flynn, Wayne Froman y Robert Vallier (eds.), Merleau-Ponty and the possibilities of philosophy: transforming the tradition, New York, SUNY Press.

HASS, LAWRENCE (2008), Merleau-Ponty's philosophy, Bloomington, Indiana University Press. 
LOW, DOUGLAS (2000), Merleau-Ponty's Last Vision. A proposalfor the Completion of The Visible and The Invisible, Evanston, Northwestern University Press.

MERLEAU-PONTY, MAURICE (1945), Phénoménologie de la perception, Paris, Gallimard. Traducción castellana: Merleau-Ponty, Maurice (1985), Fenomenología de la percepción, Barcelona, Planeta-Agostini.

_- - (1964), Le visible et l'invisible, Paris, Gallimard. Traducción castellana: Merleau-Ponty, Maurice (2010) Lo visible y lo invisible, Buenos Aires, Nueva Visión.

- - - (1963), Les sciences de l'homme et la phénoménologie, Paris, Centre de Documentation Universitaire. Traducción castellana: Merleau-Ponty (s/f) La fenomenología y las ciencias del hombre, Buenos Aires, Ed. Nova.

PIETERSMA, HENRY (1989), «Merleau-Ponty's Theory of Knowledge», en Pietersma (ed.), Merleau-Ponty: Critical Essays, Lanham-London, The Center for Advanced Research in Phenomenology-University Press of America.

- - , (2000), Phenomenological Epistemology, Oxford University Press, New York-Oxford.

SABOT, PHILIPPE (2013), « Foucault et Merleau-Ponty : un dialogue impossible ? », Les Études philosophiques, № 106.

SACRINI, MARCUS (2013), «Merleau-Ponty's Responses to Skepticism. A Critical Appraisal», International Journal of Philosophical Studies, Vol. 21, No. 5.

TOADVINE, TED (2002), «Merleau-Ponty's Reading of Husserl-A Chronological Overview». Appendix to Merleau-Ponty's Reading of Husserl, Ted Toadvine and Lester Embree (eds.), Dordrecht: Kluwer Academic Publishers.

Claudio Cormick es becario doctoral del Consejo Nacional de Investigaciones Científicas y Técnicas (CONICET) y profesor en Universidad CAECE y Universidad Nacional de Avellaneda (UNDAV). Doctorando en la Universidad de Buenos Aires (UBA) en co-tutela con Université Paris VIII (Vincennes-Saint-Denis), ha entregado su tesis que será defendida en noviembre del presente año.

Publicaciones recientes:

«Sobre la noción de responsabilidad histórica a partir de Merleau-Ponty», Areté: revista de filosofía, 2016

«Merleau-Ponty, Foucault et l'autonomie de la conscience» Bulletin d'analyse phénoménologique, XII, 6, 2016.

«'Duplicado empírico-trascendental' y 'escatología': una vez más sobre las críticas de Foucault a Merleau-Ponty»,Dianoia. Anuario de filosofía, 2017 (en prensa). 
Línea de investigación:

La tesis doctoral del autor se ha centrado en la relación de las teorías del conocimiento de Merleau-Ponty y Foucault con debates contemporáneos sobre la "situacionalidad" del conocimiento humano. Actualmente se encuentra explorando los cruces entre la fenomenología y los debates sobre el naturalismo en filosofía analítica.

Dirección postal:

Tucumán $3775,7^{\circ} \mathrm{A}$,

Ciudad Autónoma de Buenos Aires, Argentina

Dirección electrónica: claudiocormick@yahoo.com.ar

Líneas de investigación

Publicaciones recientes:

Email: 